\title{
Pharmacogenetic testing in population of South Ural
}

\author{
V.O. Barysheva* and G.G. Ketova \\ South Ural State Medical University, Scientific-educational Center Clinical Pharmacology, \\ Chelyabinsk, Russia
}

*Corresponding author. E-mail: valeriya.bar@mail.ru

\begin{abstract}
BACKGROUND: Drug resistance is a phenomenon that has received serious attention in recent years in everyday medical practice. This may also be described as responsiveness or non-responsiveness to drugs, as patients respond partially to medical treatment or have no response at all [1]. The nonresponsiveness to clopidogrel in cardiac patients of different populations is due to genetic variations in the cytochrome P450 (CYP) gene [2]. Carriers of at least one 'poor metabolizer allele' of CYP2C19 (either $* 2$ or *3) have lower levels of the active metabolite of clopidogrel and have reduced platelet inhibition [3]. Furthermore, the significant inter-ethnic variability in the allelic frequencies of CYP2C19*2 has been associated with differential clopidogrel resistance [4]. Such mutations in this variant allele are responsible for the inability of the CYP enzyme to convert clopidogrel into its active metabolite, which may result in the increased risk of death, heart attack or stroke among patients who have undergone percutaneous coronary intervention (PCI) [5]. South Ural is a multinational region, a subject of the Russian Federation, where genetic variations have not been studied fully yet.
\end{abstract}

OBJECTIVE: To examine prevalence of mutant alleles in population of South Ural.

METHODS: We conducted pharmacogenetic testing for specific single nucleotide polymorphisms in 54 patients. The present research was conducted in the alleles CYP2C19*2 and CYP2C19*3. The data were processed using the program SPSS Statistics.

RESULTS: The mean age of patients was 58, 4 years (from 26 to 79 years). Among all patients 59.3\% were male, $40.7 \%$ of female patients.

Among the studied patients in allele CYP2C19*2, the "wild" type GG was detected in $75,9 \%$ of patients, GA type in $22.2 \%$ and AA variant was detected in $1.9 \%$ of all patients. Allele CYP2C19*3 is often found among alleles with reduced function and also associated with resistance to clopidogrel. Functional drug response is observed in patients with type GG. All of the studied patients were carriers of this type. According to literature data the frequency of genotypes associated with resistance to clopidogrel in the Russian population is $11.4 \%$, which is comparable with European ethnic groups [6].

CONCLUSIONS: It was revealed that $75,9 \%$ of patients were sensitive to clopidogrel, and for them this drug in its standard dosage will be effective, and $24,1 \%$ of patients were not sensitive, therefore, they would require replacement of clopidogrel with another drug.

Keywords: Clopidogrel, pharmacogenetic testing, CYP, single nucleotide polimorphism 


\section{Conflict of interest statement: None.}

\section{References}

[1] Ding Z, Kim S, Dorsam RT, Jin J, Kunapuli SP. Inactivation of the human P2Y12 receptor by thiol reagents requires interaction with both extracellular cysteine residues, Cys17 and Cys270. Blood. 2003;101(10):3908-14. doi: http://dx.doi. org/10.1182/blood-2002-10-3027. Epub 2003 Jan 30.

[2] Sibbing, D., Stegherr, J., Latz, W., Koch, W., Mehilli, J., Dorrler, K., Morath, T., Schomig, A., Kastrati, A. and von Beckerath, N. (2008). Cytochrome P450 2C19 loss-of-function polymorphism and stent thrombosis following percutaneous coronary intervention. Eur Heart J. 2009;30(8):916-22. doi: 10.1093/eurheartj/ehp041. Epub 2009 Feb 4.

[3] Ferreiro JL, Angiolillo DJ. Clopidogrel response variability: Current status and future directions. Thromb Haemost. 2009;102(1):7-14. doi: 10.1160/TH09-03-0185.

[4] Chan M. Clopidogrel pharmacogenetics of east, south and other Asian populations. European Heart Journal Supplements. 2012. 14(Supplement A), A41-A42. doi:10.1093/eurheartj/sur035

[5] Rehman KU, Akhtar T, Sabar MF, Tariq MA. Allele frequency distribution of CYP2C19*2 allelic variants associated with clopidogrel resistance in cardiac patients. Exp Ther Med. 2015;10(1):309-15. doi: 10.3892/etm.2015.2493 Epub 2015 May 14

[6] Gaikovitch EA, Cascorbi I, Mrozikiewicz PM, Brockmöller J, Frötschl R, Köpke K, Gerloff T, Chernov JN, Roots I. Polymorphisms of drug-metabolizing enzymes CYP2C9, CYP2C19, CYP2D6, CYP1A1, NAT2 and of P-glycoprotein in a Russian population. Eur J Clin Pharmacol. 2003;59(4):303-12. doi: 10.1007/s00228-003-0606-2 Epub 2003 Jul 15. 